\section{The effect of patient and prosthesis factors on revision rates after total knee replacement using a multi-registry meta-analytic approach}

\author{
Peter L LEWIS ${ }^{1,3}$, Annette W-DAHL ${ }^{2,3}$, Otto ROBERTSSON ${ }^{\dagger}{ }^{2,3}$, Michelle LORIMER ${ }^{1}$, \\ Heather A PRENTICE ${ }^{4}$, Stephen E GRAVES ${ }^{1}$, and Elizabeth W PAXTON 4
}

\author{
${ }^{1}$ Australian Orthopaedic Association National Joint Replacement Registry, South Australian Health and Medical Research \\ Institute, Adelaide, SA Australia; ${ }^{2}$ Swedish Knee Arthroplasty Register, Lund, Sweden; ${ }^{3}$ Lund University, Faculty of Medicine, \\ Clinical Science Lund, Department of Orthopedics, Lund, Sweden; ${ }^{4}$ Surgical Outcomes and Analysis, Kaiser Permanente, San \\ Diego, CA, USA \\ Correspondence: plewis@aoanjrr.org.au \\ Submitted 2021-09-20. Accepted 2022-01-02.
}

† Otto Robertsson died October 2nd 2021. Dr Michael Dunbar, an old friend to Otto, wrote an obituary for the Knee Society, see postscript on page 293.

Background and purpose - Characteristics of patients receiving total knee arthroplasty (TKA) and prostheses used vary between regions and change with time. How these practice variations influence revision remains unclear. We combined registry data for better understanding of the impact of variation, which could potentially improve revision rates.

Patients and methods - We used data from 2003 to 2019 for primary TKA from arthroplasty registries of Sweden (SKAR), Australia (AOANJRR), and Kaiser Permanente (KPJRR). We included 1,072,924 TKA procedures for osteoarthritis. Factors studied included age, sex, ASA class, BMI category, prosthesis constraint, fixation, bearing mobility, patellar resurfacing, and polyethylene type. Cumulative percentage revision (CPR) was calculated using KaplanMeier estimates, and unadjusted Cox hazard ratios were used for comparisons. Random-effects generic inverse-variance meta-analytic methods were used to determine summary effects.

Results - We found similarities in age and sex, but between-registry differences occurred in the other 7 factors studied. Patients from Sweden had lower BMI and ASA scores compared with other registries. Use of cement fixation was similar in the SKAR and KPJRR, but there were marked differences in patellar resurfacing and posterior stabilized component use. Meta-analysis results regarding survivorship favored patients aged $\geq 65$ years and minimally stabilized components. There were inconsistent results with time for sex, fixation, and bearing mobility, and no differences for the patellar resurfacing or polyethylene type comparisons.

Interpretation - Marked practice variation was found. Use of minimally stabilized and possibly also cemented and fixed bearing prostheses is supported.
Total knee arthroplasty (TKA) prosthesis survivorship is $>95 \%$ at 10 years (1-3). TKA revision rates vary according to the region $(4,5)$ and over time $(1,6)$. However, how these differences affect revision rates remains unclear, or whether improvement is possible choosing certain TKA attributes.

Patient factors that influence TKA survivorship include age $(5,7)$, sex $(8)$, obesity $(9,10)$, and comorbidity $(11,12)$. Key prosthesis factors are prosthesis constraint $(\mathbf{1 3}, \mathbf{1 4})$, bearing mobility $(15,16)$, fixation method $(17,18)$, patellar resurfacing $(19,20)$, and polyethylene type $(21,22)$.

Randomized trials are unsuitable for studying these factors, as strict inclusion/exclusion criteria and use of standardized prostheses may complicate generalizability. Registry studies are limited by prosthesis choice confounding, and difficulty in assessing each factor's influence. Propensity score matching and instrumental variable analysis are methods to reduce selection bias, but these may still not control for unmeasured confounding, or fit the assumption of instrument and outcome independence $(23,24)$.

Considerable practice variability exists among specialist TKA surgeons both within and between countries $(25,26)$. An example is patellar resurfacing rates, which varied from $4 \%$ in Norway to $82 \%$ in the USA (27). These differences provide opportunity to explore variables that may influence prosthesis survivorship (a "natural experiment") (28). Combining data may balance distortions resulting from differential prosthesis use, enhancing understanding of the relationship between these factors and revision rates. Sharing even de-identified patient data is often not possible due to data ownership regulations and concerns regarding privacy and data security. Using a meta-analytic approach to pool registry data has proven utility, being shown to be similar to individual patient-level data analysis (29). 
In a previous study we found inter-registry differences regarding reasons for knee replacement revision and theorized this was related to patient selection and prosthesis choice (30). This study (i) documents regional and temporal variation in primary TKA practice across 3 registries between 2003 and 2019 and (ii) uses a meta-analytic technique to determine the influence of each factor on the risk of revision.

\section{Patients and methods}

We obtained aggregate annual data for the period January 1, 2003 until December 31, 2019 for all primary TKA procedures recorded in the Swedish Knee Arthroplasty Register (SKAR), the Australian Orthopaedic Association National Joint Replacement Registry (AOANJRR), and the Kaiser Permanente Joint Replacement Registry (KPJRR). Only TKA for osteoarthritis (OA) was included. Partial knee arthroplasties, revision TKA, and TKA for pathologies other than OA were excluded. The completeness of these registries exceeds $95 \%$ and loss to follow-up was less than $8 \%$ over the study period. Validation and quality control methods of these registries have been published $(2,31,32)$.

There were $1,072,924$ primary TKA for OA included $(188,290$ from the SKAR, 663,982 from the AOANJRR, and 220,652 from the KPJRR). Patient factors recorded were age, sex, ASA score, and body mass index (BMI). As the SKAR and AOANJRR began collecting ASA and BMI data at later time points, these categories permitted limited analyses.

We analyzed 5 prosthesis factors. Prosthesis constraint was divided into minimally stabilized (MS) (those that have a flat or dished tibial articulation, regardless of congruency), posterior stabilized (PS) (implants that provide posterior stability using a peg and box design), fully stabilized (FS) (implants with a large peg and box design designed to give some collateral as well as posterior stability), and hinged (implants with a hinge mechanism to link the femoral and tibial components). Fixation was cemented (both femoral and tibial components cemented), cementless (both components inserted without cement), and hybrid (tibial or femoral component only cemented). Bearing mobility was either mobile (inserts designed to move relative to the tibial base-plate) or fixed (components designed not to move relative to the tibial base-plate). Patellar resurfacing components were either used or not used. Polyethylene type was ultra-high molecular weight polyethylene (UHMWPE), highly cross-linked (XLPE, classified as ultrahigh molecular weight polyethylene that has been irradiated by high dose ( $>$ $50 \mathrm{kGy}$ ) gamma or electron beam radiation) and highly crosslinked polyethylene with antioxidant (combining vitamin $\mathrm{E}$ and Covernox; DePuy Synthes. Warsaw, IN, USA) (XLPE + AntiOx). The proportions of the alternatives for these categories were calculated and trends assessed over time.

For the meta-analyses, either the measure was dichotomized or, if there were more than 2 alternatives for a factor, the 2 most common categories were selected for analysis. This approach minimized the number of comparisons. Age was divided into $<65$ years and compared with $\geq 65$ years of age. For analysis of ASA, scores 1 and 2 were combined to compare those with no or mild systemic disease with those with severe disease (ASA scores 3 and over). For BMI, the nonobese group (with a BMI <30) were compared with the obese $(B M I \geq 30)$. For the analyses of prosthesis constraint, minimally stabilized were compared with posterior stabilized (as fully stabilized and hinged prostheses made up less than $1 \%$ of primary TKA), cement fixation was compared with cementless fixation (as hybrid fixation was rarely used in the SKAR and KPJRR), and for polyethylene type XLPE and XLPE + AntiOx were combined for comparison with UHMWPE.

\section{Statistics}

Kaplan-Meier estimates of survivorship were used to report the time to revision, with censoring at the time of death and closure of each dataset at the end of December 2019. Patients in the KPJRR were also censored if they ended membership with the healthcare plan. The cumulative percentage revision (CPR) rates, with $95 \%$ confidence intervals $(\mathrm{CI})$, were calculated using point-wise Greenwood estimates. For each registry, hazard ratios (HR) were calculated from Cox models to compare the rate of revision between groups. In order to combine the hazards, knowing that these ratios can vary with time, we used unadjusted ratios calculated for each pair of variables of interest at 5, 10, and 15 years from surgery. All tests were twotailed and 0.05 was the significance threshold. Analyses were performed using SAS version 9.4 (33) for the AOANJRR and KPJRR data, and STATA release 15 (34) for the Swedish data.

We used software from R (Version V.3.1.2) (35) using the General Package for Meta-analysis for the generic inversevariance method for calculating a total treatment effect at each time-point for each variable. The random-effects models were used for all analyses and 95\% confidence intervals (CI) are presented as are $95 \%$ prediction intervals. Heterogeneity was determined by both $\mathrm{Tau}^{2}$ and $\mathrm{I}^{2}$.

\section{Ethics, data sharing, funding, and potential conflicts of interest}

Ethics approval covering the SKAR data use was approved by the Ethics Board of Lund University (LU20-02). The AOANJRR is a declared Commonwealth of Australia Quality Assurance Activity under section $124 \mathrm{X}$ of the Health Insurance Act, 1973. All AOANJRR studies are conducted in accordance with ethical principles of research (Helsinki Declaration II). Approval for inclusion of data from the Kaiser Permanente Joint Replacement Registry Institutional Review Board (\#5488) was granted on November 15, 2018. A data sharing agreement for the purpose of this study was finalized on December 10, 2020 by the directors of the SKAR, AOANJRR, and KPJRR. There was no funding. There are no conflicts of interest. 
Table 1. Summary of patient factors for TKA for OA 2003-2019 by registry. Values are count (\%) unless otherwise specified

\begin{tabular}{|c|c|c|c|}
\hline & $\begin{array}{c}\text { SKAR } \\
n=188,290\end{array}$ & $\begin{array}{c}\text { AOANJRR } \\
n=663,982\end{array}$ & $\begin{array}{c}\text { KPJRR } \\
n=220,652\end{array}$ \\
\hline \multicolumn{4}{|l|}{ Sex } \\
\hline Males & $79,230(42)$ & $291,208(44)$ & 84,937 (38) \\
\hline Females & $109,060(58)$ & 372,774 (56) & 135,715 (62) \\
\hline Mean age (SD) & $\quad 69.5(8.9)$ & $68.5(9.1)$ & $67.6(8.9)$ \\
\hline \multicolumn{4}{|l|}{ Age groups } \\
\hline$<55$ & $11,164(5.9)$ & $43,508(6.6)$ & 15,915 (7.2) \\
\hline $55-64$ & $47,111(25)$ & $177,066(27)$ & $65,693(30)$ \\
\hline $65-74$ & $74,830(40)$ & $263,105(40)$ & $88,065(40)$ \\
\hline$\geq 75$ & 55,185 (29) & $180,303(27)$ & $50,979(23)$ \\
\hline ASA & from 2009 & from 2013 & from 2003 \\
\hline 1 & $24,112(18)$ & 20,306 & $3,431(1.6)$ \\
\hline 2 & $88,804(65)$ & $188,640(53)$ & $124,206(56)$ \\
\hline 3 & $22,426(16)$ & $128,551(36)$ & 73,502 (33) \\
\hline 4 & $249(0.2)$ & $3,672(1.0)$ & $1,769(0.8)$ \\
\hline 5 & $9(0.0)$ & $10(0.0)$ & $13(0.0)$ \\
\hline Missing & $1,348(1.0)$ & $14,891(4.2)$ & $17,731(8.0)$ \\
\hline BMI & from 2009 & from 2015 & from 2003 \\
\hline Underweight & $\mathrm{t} \quad 214(0.2)$ & $439(0.2)$ & $393(0.2)$ \\
\hline Normal & $24,483(18)$ & 25,581 (9.6) & 25,849 (12) \\
\hline Pre-obese & 58,839 (43) & 77,407 (29) & $69,110(3.1)$ \\
\hline Obese 1 & 38,000 (28) & 76,861 (29) & 66,968 (30) \\
\hline Obese 2 & $11,565(8.4)$ & 42,505 (16) & $37,882(17)$ \\
\hline Obese 3 & $2,436(1.8)$ & $26,499(10)$ & $14,524(6.6)$ \\
\hline Missing & $1,411(1.0)$ & 16,641 (6.3) & $5,926(2.7)$ \\
\hline
\end{tabular}

\section{Results}

\section{Overall results}

The age and sex of TKA patients were similar between registries. There was a higher proportion of TKA patients in Sweden with no or mild systemic disease and without obesity (Table 1).

Prosthesis factors showed greater variation. Minimally stabilized prostheses were used in 93\% of TKA in Sweden, $73 \%$ in Australia, but in only 30\% in the KPJRR. Surgeons in the KPJRR preferred PS prostheses in 67\% of TKA. Cement fixation of both components was favored in $96 \%$ and $94 \%$ of procedures in the SKAR and KPJRR, but in only 59\% in the AOANJRR. The remaining cases in Australia were hybrid (tibial component cemented) (22\%) or cementless (18\%). All registries had over $80 \%$ fixed bearing use. Patellar resurfacing showed greatest variation: $4 \%$ in the SKAR, $98 \%$ in the KPJRR, and 57\% in the AOANJRR. UHMWPE was used in the majority of procedures in all countries (Table 2).

\section{Time-related trends}

In all registries, the mean age of TKA recipients initially showed a small decline but a minor increase in the last 3-4 years. There was a reduction in the percentage of females in all registries with time (Figure 1).

The major difference between Sweden and the KPJRR for the use of MS TKA persisted with little change, while the pro-
Table 2. Summary of prosthesis factors for TKA for OA by registry. Values are count $(\%)$

\begin{tabular}{lrrr}
\hline & SKAR & AOANJRR & \multicolumn{1}{c}{ KPJRR } \\
& $\mathrm{n}=188,290$ & $\mathrm{n}=663,982$ & $\mathrm{n}=220,652$ \\
\hline Prosthesis constraint & & & \\
Minimally stabilized & $175,667(93)$ & $487,626(73)$ & $66,489(30)$ \\
Posterior stabilized & $11,340(6.0)$ & $172,530(26)$ & $146,780(67)$ \\
Fully stabilized & $758(0.4)$ & $2,519(0.4)$ & $3,210(1.4)$ \\
Hinged & $470(0.2)$ & $1,133(0.2$ & $64(0.0)$ \\
Missing & $55(0.0)$ & $174(0.0)$ & $5,009(2.3)$ \\
Fixation & & & \\
Both cemented & $180,220(96)$ & $389,650(59)$ & $208,391(94)$ \\
Both cementless & $7,424(3.9)$ & $120,616(18)$ & $3,746(1.7)$ \\
Tibia only cemented & $136(0.1)$ & $147,232(22)$ & $6,387(2.9)$ \\
Femur only cemented & $277(0.1)$ & $6,484(1.0)$ & $357(0.2)$ \\
Missing & $233(0.1)$ & $0(0)$ & $1,771(0.8)$ \\
Bearing mobility & & & \\
Fixed & $186,680(99)$ & $539,194(81)$ & $202,426(92)$ \\
Mobile & $1,461(0.8)$ & $124,614(19)$ & $13,208(6.0)$ \\
Missing & $149(0.1)$ & $174(0.0)$ & $5,018(2.3)$ \\
Patellar component & & & \\
Used & $7,975(4.2)$ & $375,409(57)$ & $215,924(98)$ \\
Not used & $180,315(96)$ & $288,573(44)$ & $4,728(2.1)$ \\
Polyethylene type & & & \\
UHMWPE & $162,648(86)$ & $395,665(60)$ & $147,384(67)$ \\
XLPE & $24,473(13)$ & $230,781(35)$ & $36,750(17)$ \\
XLPE + AntiOx. & $495(0.3)$ & $37,255(5.6)$ & $24,156(11)$ \\
Missing & $674(0.4)$ & $281(0.0)$ & $12,362(5.6)$ \\
\hline & & & \\
\hline & &
\end{tabular}

portion in Australia varied from $67 \%$ to $83 \%$. The use of PS TKA varied between $57 \%$ and $70 \%$ in the KPJRR, rose from $17 \%$ to $32 \%$ in Australia until 2010 but declined to $19 \%$ in 2019, while in Sweden PS use remained below 9\% for the entire period. Cement fixation was consistently used in $>93 \%$ and $>88 \%$ of TKA in the SKAR and the KPJRR respectively, while increasing in the AOANJRR from $44 \%$ to $68 \%$.

Mobile bearing prostheses have never been popular in Sweden, used in a maximum of $2 \%$ of procedures, while a decline in the use with time was observed in both Australia and the KPJRR. The patellar resurfacing tendency remained low in Sweden (11\% falling to 2\%), while in the KPJRR patellar component use was consistently high (over 97\%). In Australia, patellar resurfacing rose from $44 \%$ to $73 \%$. There was a trend for increased use of XLPE (Figure 2).

\section{Meta-analysis of patient and prosthesis factors}

Meta-analysis showed a higher revision risk associated with age $<65$ years, with increasing summary hazard ratios over time (HR 1.6 at 5 years, HR 2.0 at 10 years, and HR 2.2 at 15 years). Males showed a higher risk of revision compared with females in the first 5 years (HR 1.2), but after this no difference was observed. Patients with severe systemic disease showed a higher risk of revision at 5 years compared with patients with no or mild systemic disease (HR 1.3), as did obese patients when compared with non-obese (HR 1.2). The prediction interval for each of these analyses contained 1 (Figure 3, see Supplementary data). 

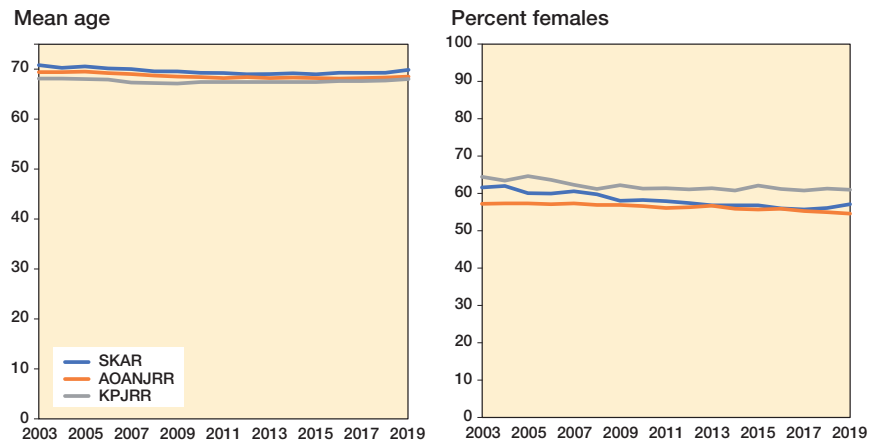

Figure 1. Time-related trends in patient factors in TKA for OA for each registry.

Prosthesis factor meta-analysis showed a higher risk of revision for PS TKA compared with MS (HR 1.4 at 5 years and HR 1.3 at both 10 years and 15 years) at all time-point comparisons. Cementless fixation gave a higher risk of revision compared with cemented fixation (HR 1.3 at both 5 years and 15 years) but no risk difference at 10 years. Mobile bearing TKA had a higher risk of revision compared with fixed bearing at 5 years (HR 1.6) but at 10 and 15 years there was no observed difference. Analysis of patellar component use showed no observed difference in risk of revision with or without patellar resurfacing. There was no revision risk difference associated with the use of XLPE when compared with UHMWPE, but limited data allowed analysis only to 10 years. Only for the analysis of fixation at 5 years did the prediction interval not include 1 (Figure 4, see Supplementary data).

\section{Discussion}

We described the international and time-related similarities and differences in primary TKA surgery between 3 distinct registries. Similarities were seen with age and sex, but between-registry differences occurred in the other 7 factors studied, with prosthesis constraint and patellar component use showing the greatest diversity. There were common trends over time for increased use of fixed bearing prostheses and XLPE inserts. Meta-analysis showed consistent findings for survivorship favoring patients aged $\geq 65$ years and minimally stabilized components. There were findings favoring female sex, cement fixation, and fixed bearing components at some of the time comparisons, and no differences at any time were shown with analyses of patellar component use or polyethylene type.

Previous studies comparing registry-recorded characteristics have been limited to a comparison of 2 areas (36), or a localized region, such as the Nordic Arthroplasty Register Association $(37,38)$. Others have extracted data from the annual reports from different registries (39) or used a distributed data network $(\mathbf{1 4}, 15)$. Previous meta-analytic approaches using registry data have been used to assess the overall revi-
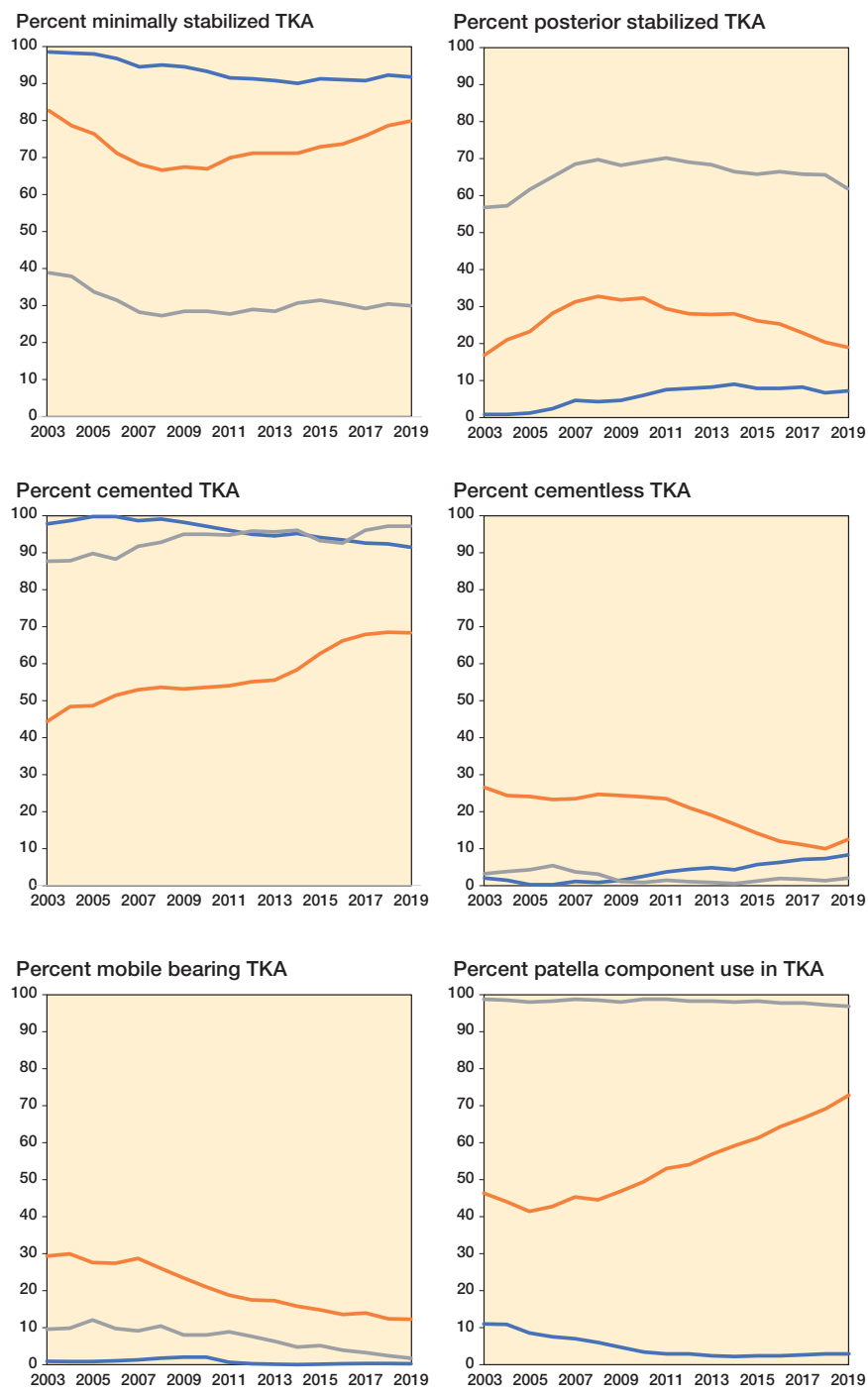

Figure 2. Time-related trends in prosthesis factors in TKA for $\mathrm{OA}$ for each registry. For color codes, see Figure 1.

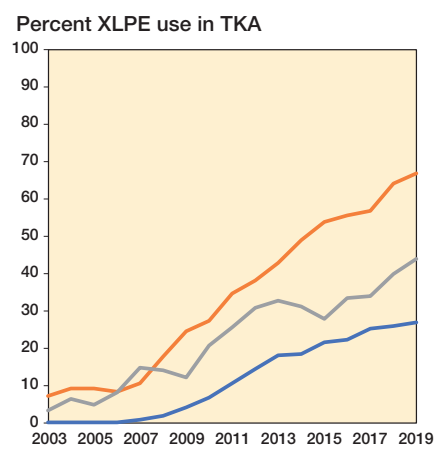

sion rate (40) or individual factors such as fixation (41), but there has been no previous study of multiple factors.

The patient-related meta-analytic summary findings regarding lower revision risk favored age $\geq 65$ years, those with no or mild systemic disease, and those considered non-obese. The concordance of individual registry results for these factors suggests reliability of these findings. Younger age is a 
known risk for TKR revision. Obesity was shown in a systematic review to have a higher all-cause and septic revision risk (9). The relationship of comorbidity to revision has been shown to relate not just to obesity, but also to iron-deficiency anemia and liver disease (11). We found female sex was associated with a lower risk of revision at 5 years, consistent with studies showing males with a higher early risk of revision related to infection $(\mathbf{8 , 4 2})$.

The finding in favor of lower risk of revision using MS components was strongest in Sweden where these designs were used for over $90 \%$ of TKA. A higher rate of revision with PS prostheses was also seen in the KPJRR where PS components were far more popular, and in Australia where there was mixed use of both constraint types. The similarity of the findings despite the usage differences increases the weight of this evidence. While there has been persistent debate regarding prosthetic constraint, with some claiming no difference in revision rate (43), our results are consistent with the claim of superiority of the MS designs $(13,44)$.

Cement fixation gave a lower risk of revision when compared with cementless fixation at 5 and 15 years. Cement may protect against early migration and revision for loosening (45). Cement fixation for TKA has been termed the "gold standard" and has consistently been reported to be superior to cementless fixation $(18,37,46)$. However, there has been support for the contrary viewpoint (17).

While there were differences between registries, mobile bearing prostheses overall had a higher risk of revision compared with fixed bearing at 5 years, but showed no difference at 10 and 15 years. This difference may be explained by bearing dislocation and instability that occur early in the mobile group (47). Mobile bearings were used in less than $20 \%$ of TKA in all registries during the study period. Our study endorses the trend to declining use of these designs, and confirms the results of previous studies $(15,48,49)$.

Analysis of patellar resurfacing showed divergent usage and revision results. In the KPJRR, where patellar resurfacing is commonplace, revision risk analyses favored patellar component use, but the converse was found in the SKAR where the usual practice of not resurfacing was shown to have lower revision rates. In the AOANJRR, where patellar component use varied, there were lower revision rates at 5 and 10 years with patellar resurfacing, but no difference at 15 years. While some studies have shown lower early revision rates with patellar resurfacing, there are concerns about wear and loosening in

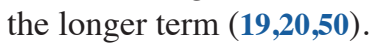

XLPE use increased in all registries, but we observed no revision risk difference with its use compared with UHMWPE. Results showed a wide variation at 5 years with XLPE giving a lower revision risk in Australia, but UHMWPE gave better revision results in Sweden. These analyses most likely reflect results of limited prostheses that offer XLPE. Of note is the increased use, which seems to be market-driven, rather than a response to registry-recorded outcomes. A "no difference" finding for all-cause revision is consistent with other studies $(\mathbf{5 1 , 5 2 )}$.

With some analyses, low usage of certain types of prostheses resulted in higher revision rates with that choice, and this may reflect selective use in difficult or specific clinical settings, limited prosthesis selection, or lack of familiarity with the procedure. This could explain some of the differences in the magnitude of hazard ratios.

Among the registries studied there was considerable heterogeneity, as in all but 2 of the 22 meta-analyses the measure of heterogeneity $\left(\mathrm{I}^{2}\right)$ was 70 or above. As each registry uses similar approaches to data collection and analysis, there is little methodological difference, and so the heterogeneity seen in this study would relate to clinical diversity. According to Cochrane methodology (53), heterogeneity should diminish the certainty of the findings. However, we argue that where there are consistent findings despite differences in populations studied this should strengthen the validity of the results. The finding of heterogeneity also led to use of the random-effects models for meta-analysis. An advantage of the random-effects model, when compared with the fixed-effects model, is that the number of procedures each registry contributes has a smaller influence on the results, diminishing potential inequality from the larger volume Australian registry. For comparisons (other than fixation at 5 years) the prediction interval assessments cast some uncertainty on the findings. This interpretation suggests that there may be circumstances in which the alternative to a favored factor has the better outcome.

There are a number of limitations of this study. Only 3 registries were included, and more robust conclusions could be drawn by the inclusion of even more data. Analysis of observational data can be affected by unmeasured confounding. We studied only 9 factors relating to TKA surgery, and there are other factors, such as patient activity levels or surgeon experience, that influence revision rates in addition those studied. Each factor was analyzed independently but there may be interaction between the factors studied, such as different rates of revision with PS and MS prostheses without patellar component use. Also, consistent with other registry studies, revision was the chosen outcome measure, but different results might have been found with other measures, such as those assessing function or satisfaction. We have used all-cause revision rates, and it is possible that if more focused reasons for revision were used (such as revision for loosening when analyzing fixation) different results could be found. Also, the comparisons considered prosthesis factors as distinct groups, but there are known prosthesis-specific performance differences (54). In addition, with some factors studied there was insufficient follow-up to allow analysis at all time points.

Why surgeons use specific prostheses for knee replacement surgery is poorly understood. A multi-national survey of TKA surgeons found "lowest registry revision risk" only rated 10th out of 17 attributes regarding prosthesis choice (26). It is hoped that, as evidence regarding the factors related to TKA 
revision increases, there will be a parallel increase in the influence that registry results have on surgeon choices.

In conclusion, while patient factors have little potential for change, altered prosthesis selection can possibly increase TKA survivorship. Our study suggests that the use of minimally stabilized, and possibly also fixed bearing prostheses, used with cement fixation result in a lower risk of revision. These styles are already common in the SKAR, but patients from the AOANJRR and the KPJRR may benefit from increased choice of these designs. Further study is required to assess the influence of patellar resurfacing and XLPE use.

PLL: literature search, study design, methodology determination, data collection, data analysis, data synthesis, manuscript writing. AWD: Study design, interpretation of data, manuscript preparation. OR: Methodology advice, data analysis, interpretation of data, manuscript preparation. ML: Data analysis, methodology advice. HAP: Data analysis, manuscript preparation. SEG: Interpretation of data, manuscript preparation. EWP: Interpretation of data, manuscript preparation.

The authors would like to thank the patients and surgeons who contribute their valuable data to the SKAR, AOANJRR, and KPJRR, without which studies such as this would not be possible. They also acknowledge the valuable assistance given by Dr Sophie Rainbird and Dr David Campbell to aid finalization of this manuscript.

Acta thanks Mika Niemeläinen and Marina Torre for help with peer review of this study.

1. SKAR. Swedish Knee Arthroplasty Register Annual Report 2020. Lund University: Lund, Sweden; 2020. Available from https://www.myknee. se/pdf/SVK_2020_Eng_1.0.pdf (retrieved June 10, 2021).

2. AOANJRR. AOANJRR Hip, Knee and Shoulder Arthroplasty: 2020 Annual Report. Adelaide AOA; 2020. Available from https://aoanjrr. sahmri.com/annual-reports-2020 (retrieved June 15, 2021).

3. NJR. National Joint Registry 17th Annual Report; 2020. Available from https://reports.njrcentre.org.uk/Portals/0/PDFdownloads/NJR\%20 17th\%20Annual\%20Report\%202020.pdf (retrieved June 15, 2021).

4. Robertsson O, Bizjajeva S, Fenstad A M, Furnes O, Lidgren L, Mehnert F, et al. Knee arthroplasty in Denmark, Norway and Sweden: a pilot study from the Nordic Arthroplasty Register Association. Acta Orthop 2010; 81(1): 82-9.

5. Price A J, Alvand A, Troelsen A, Katz J N, Hooper G, Gray A, et al. Knee replacement. Lancet 2018; 392(10158): 1672-82.

6. Gøthesen O, Espehaug B, Havelin L, Petursson G, Lygre S, Ellison $\mathbf{P}$, et al. Survival rates and causes of revision in cemented primary total knee replacement: a report from the Norwegian Arthroplasty Register 1994-2009. Bone Joint J 2013; 95-B(5): 636-42.

7. Jorgensen N B, McAuliffe M, Orschulok T, Lorimer M F, de Steiger R. Major aseptic revision following total knee replacement: a study of 478,081 total knee replacements from the Australian Orthopaedic Association National Joint Replacement Registry. J Bone Joint Surg Am 2019; 101(4): 302-10.

8. Brown M J, Koh N P, Bell S W, Jones B, Blyth M. Age and gender related differences in infection, thromboembolism, revision and death in knee arthroplasty in a Scottish population. Scott Med J 2020; 65(3): 89-93.

9. Chaudhry H, Ponnusamy K, Somerville L, McCalden R W, Marsh J, Vasarhelyi E M. Revision rates and functional outcomes among severely, morbidly, and super-obese patients following primary total knee arthroplasty: a systematic review and meta-analysis. JBJS Rev 2019; 7(7): e9.
10. Si H B, Zeng Y, Shen B, Yang J, Zhou Z K, Kang P D, et al. The influence of body mass index on the outcomes of primary total knee arthroplasty. Knee Surg Sports Traumatol Arthrosc 2015; 23(6): 1824-32.

11. Arias-de la Torre J, Smith K, Dregan A, Valderas J M, Evans J P, Prieto-Alhambra D, et al. Impact of comorbidity on the short- and medium-term risk of revision in total hip and knee arthroplasty. BMC Musculoskelet Disord 2020; 21(1): 447.

12. Hooper G J, Rothwell A G, Hooper N M, Frampton C. The relationship between the American Society if Anesthesiologists physical rating and outcome following total hip and knee arthroplasty: an analysis of the New Zealand Joint Registry. J Bone Joint Surg Am 2012; 94(12): 1065-70.

13. Vertullo C J, Lewis P L, Lorimer M, Graves $\mathbf{S} \mathbf{E}$. The effect on longterm survivorship of surgeon preference for posterior-stabilized or minimally stabilized total knee replacement: an analysis of 63,416 prostheses from the Australian Orthopaedic Association National Joint Replacement Registry. J Bone Joint Surg Am 2017; 99(13): 1129-39.

14. Comfort T, Baste V, Froufe M A, Namba R, Bordini B, Robertsson $\mathbf{O}$, et al. International comparative evaluation of fixed-bearing non-posterior-stabilized and posterior-stabilized total knee replacements. J Bone Joint Surg Am 2014; 96(Supplement_1): 65-72.

15. Graves S, Sedrakyan A, Baste V, Gioe T J, Namba R, Cruz O M, et al. International comparative evaluation of knee replacement with fixed or mobile-bearing posterior-stabilized prostheses. J Bone Joint Surg Am 2014; 96(Supplement_1): 59-64.

16. Fransen B L, van Duijvenbode D C, Hoozemans M J M, Burger B J. No differences between fixed- and mobile-bearing total knee arthroplasty. Knee Surg Sports Traumatol Arthrosc 2017; 25(6): 1757-77.

17. Newman J M, Sodhi N, Dekis J C, Khlopas A, Piuzzi N S, Sultan A A, et al. Survivorship and functional outcomes of cementless versus cemented total knee arthroplasty: a meta-analysis. J Knee Surg 2020; 33(3): 270-8

18. Vertullo C J, Graves S E, Peng Y, Lewis P L. The effect of surgeon's preference for hybrid or cemented fixation on the long-term survivorship of total knee replacement. Acta Orthop 2018; 89(3): 329-35.

19. Longo U G, Ciuffreda M, Mannering N, D'Andrea V, Cimmino M, Denaro V. Patellar resurfacing in total knee arthroplasty: systematic review and meta-analysis. J Arthroplasty 2018; 33(2): 620-32.

20. Vertullo C J, Graves S E, Cuthbert A R, Lewis P L. The effect of surgeon preference for selective patellar resurfacing on revision risk in total knee replacement: an instrumental variable analysis of 136,116 procedures from the Australian Orthopaedic Association National Joint Replacement Registry. J Bone Joint Surg Am 2019; 101(14): 1261-70.

21. Vertullo C J, de Steiger R N, Lewis P L, Lorimer M, Peng Y, Graves $\mathrm{S} \mathrm{E}$. The effect of prosthetic design and polyethylene type on the risk of revision for infection in total knee replacement: an analysis of 336,997 prostheses from the Australian Orthopaedic Association National Joint Replacement Registry. J Bone Joint Surg Am 2018; 100(23): 2033-40.

22. Boyer B, Bordini B, Caputo D, Neri T, Stea S, Toni A. Is cross-linked polyethylene an improvement over conventional ultra-high molecular weight polyethylene in total knee arthroplasty? J Arthroplasty 2018; 33(3): 908-14

23. Austin PC.An introduction to propensity score methods for reducing the effects of confounding in observational studies. Multivariate Behav Res 2011; 46(3): 399-424.

24. Huang H H, Cagle P J Jr, Mazumdar M, Poeran J. Statistics in brief: instrumental variable analysis: an underutilized method in orthopaedic research. Clin Orthop Relat Res 2019; 477(7): 1750-5.

25. Bosch L C, Beger S B, Duncan S T, Rossi S M P, Sculco P K, Barnes C L, et al. Intraoperative practice variability in total knee arthroplasty. J Arthroplasty 2020; 35(3): 725-31.

26. Vertullo C J, Grimbeek P M, Graves S E, Lewis P L. Surgeon's preference in total knee replacement: a quantitative examination of attributes, reasons for alteration, and barriers to change. J Arthroplasty 2017; 32(10): 2980-9.

27. Fraser J F, Spangehl M J. International rates of patellar resurfacing in primary total knee arthroplasty, 2004-2014. J Arthroplasty 2017; 32(1): 83-6. 
28. Craig P, Katikireddi S V, Leyland A, Popham F. Natural experiments: an overview of methods, approaches, and contributions to public health intervention research. Annu Rev Public Health 2017; 38: 39-56.

29. Paxton E W, Mohaddes M, Laaksonen I, Lorimer M, Graves S E, Malchau H, et al. Meta-analysis of individual registry results enhances international registry collaboration. Acta Orthop 2018; 89(4): 369-73.

30. Lewis P L, Robertsson O, Graves S E, Paxton E W, Prentice H A, W-Dahl A. Variation and trends in reasons for knee replacement revision: a multi-registry study of revision burden. Acta Orthop 2021; 92(2): $182-8$.

31. Paxton E W, Inacio M C, Khatod M, Yue E J, Namba R S. Kaiser Permanente National Total Joint Replacement Registry: aligning operations with information technology. Clin Orthop Relat Res 2010; 468(10): 2646-63.

32. Robertsson O, Ranstam J, Sundberg M, A W D, Lidgren L. The Swedish Knee Arthroplasty Register: a review. Bone Joint Res 2014; 3(7): 217-22.

33. Statistical Analysis Systems. SAS System for Windows (Release 9.4). Cary, NC: SAS Institute; 2013.

34. StataCorp. Stata Statistical Software: Release 15. College Station, TX: StataCorp LLC; 2017.

35. $\mathbf{R}$ Core Team, A language and environment for statistical computing. Vienna, Austria: R Foundation for Statistical Computing (Version V.3.1.2); 2021. Available from https://www.R-project.org/ (retrieved June 5, 2020).

36. Paxton E W, Furnes O, Namba R S, Inacio M C, Fenstad A M, Havelin L I. Comparison of the Norwegian knee arthroplasty register and a United States arthroplasty registry. J Bone Joint Surg Am 2011; 93(Suppl. 3): 20-30.

37. Irmola T, Ponkilainen V, Mäkelä K T, Robertsson O, A W D, Furnes $\mathbf{O}$, et al. Association between fixation type and revision risk in total knee arthroplasty patients aged 65 years and older: a cohort study of 265,877 patients from the Nordic Arthroplasty Register Association 2000-2016. Acta Orthop 2021; 92(1): 91-6.

38. NiemeläInen M J, MäKelä K T, Robertsson $\mathbf{O}, \mathbf{A}$ W D, Furnes $\mathbf{O}$, Fenstad A M, et al. Different incidences of knee arthroplasty in the Nordic countries. Acta Orthop 2017; 88(2): 173-8.

39. Abdelaal M S, Restrepo C, Sharkey PF. Global perspectives on arthroplasty of hip and knee joints. Orthop Clin North Am 2020; 51(2): 169-76.

40. Evans J T, Walker R W, Evans J P, Blom A W, Sayers A, Whitehouse M R. How long does a knee replacement last? A systematic review and meta-analysis of case series and national registry reports with more than 15 years of follow-up. Lancet 2019; 393(10172): 655-63.

41. Wang H, Lou H, Zhang H, Jiang J, Liu K. Similar survival between uncemented and cemented fixation prostheses in total knee arthroplasty: a meta-analysis and systematic comparative analysis using registers. Knee Surg Sports Traumatol Arthrosc 2014; 22(12): 3191-7.
42. Lenguerrand E, Whitehouse M R, Beswick A D, Kunutsor S K, Foguet P, Porter M, et al. Risk factors associated with revision for prosthetic joint infection following knee replacement: an observational cohort study from England and Wales. Lancet Infect Dis 2019; 19(6): 589-600.

43. Migliorini F, Eschweiler J, Tingart M, Rath B. Posterior-stabilized versus cruciate-retained implants for total knee arthroplasty: a meta-analysis of clinical trials. Eur J Orthop Surg Traumatol 2019; 29(4): 937-46.

44. Abdel M P, Morrey M E, Jensen M R, Morrey B F. Increased longterm survival of posterior cruciate-retaining versus posterior cruciatestabilizing total knee replacements. J Bone Joint Surg Am 2011; 93(22): 2072-8.

45. Pijls B G, Plevier J W M, Nelissen R. RSA migration of total knee replacements. Acta Orthop 2018; 89(3): 320-8.

46. Nugent M, Wyatt M C, Frampton C M, Hooper G J. Despite improved survivorship of uncemented fixation in total knee arthroplasty for osteoarthritis, cemented fixation remains the gold standard: an analysis of a National Joint Registry. J Arthroplasty 2019; 34(8): 1626-33.

47. Diamond O J, Doran E, Beverland D E. Spinout/dislocation in mobilebearing total knee arthroplasty: a report of 26 cases. J Arthroplasty 2018; 33(2): $537-43$

48. Gothesen O, Lygre S H L, Lorimer M, Graves S, Furnes O. Increased risk of aseptic loosening for 43,525 rotating-platform vs. fixed-bearing total knee replacements. Acta Orthop 2017; 88(6): 649-56.

49. Namba R S, Inacio M C, Paxton E W, Ake C F, Wang C, Gross T P, et al. Risk of revision for fixed versus mobile-bearing primary total knee replacements. J Bone Joint Surg Am 2012; 94(21): 1929-35.

50. Lygre S H, Espehaug B, Havelin L I, Vollset S E, Furnes O. Failure of total knee arthroplasty with or without patella resurfacing. Acta Orthop 2011; 82(3): 282-92.

51. Partridge T C J, Baker $\mathbf{P}$ N, Jameson S S, Mason J, Reed M R, Deehan D J. Conventional versus highly cross-linked polyethylene in primary total knee replacement: a comparison of revision rates using data from the National Joint Registry for England, Wales, and Northern Ireland. J Bone Joint Surg Am 2020; 102(2): 119-27.

52. Gkiatas I, Karasavvidis T, Sharma A K, Xiang W, Malahias M A, Chalmers B P, et al. Highly cross-linked polyethylene in primary total knee arthroplasty is associated with a lower rate of revision for aseptic loosening: a meta-analysis of 962,467 cases. Arch Orthop Trauma Surg 2021 Apr 13. doi: 10.1007/s00402-021-03887-z. Online ahead of print.

53. Deeks J, Higgins J, Altman D. Analysing data and undertaking metaanalyses In: Higgins J P T, Chandler J, Cumpston M, Li T, Page M J, Welch V A, editors. Cochrane Handbook for Systematic Reviews of Interventions, version 6.2. London: Cochrane; 2021.

54. Deere K C, Whitehouse M R, Porter M, Blom A W, Sayers A. Assessing the non-inferiority of prosthesis constructs used in total and unicondylar knee replacements using data from the National Joint Registry of England, Wales, Northern Ireland and the Isle of Man: a benchmarking study. BMJ Ope, 2019; 9(4): e026736 


\section{Supplementary data}

\section{Age at 5 years}

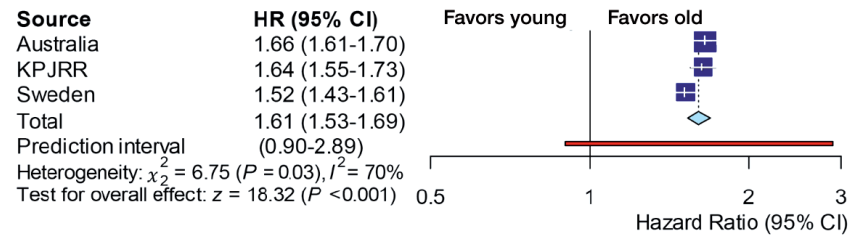

\section{Age at 10 years}

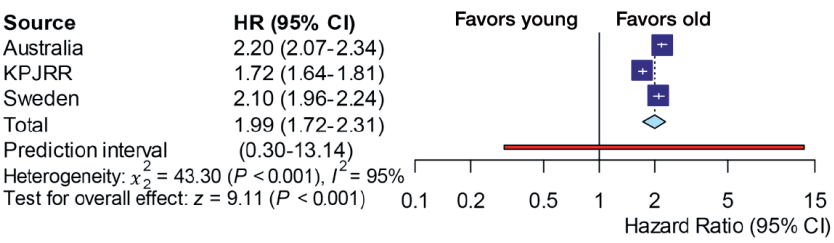

\section{Age at 15 years}

Source

Australia

KPJRR

Sweden

Total

Prediction interval

Heterogeneity: $x_{2}^{2}=77.16(P<0.001), I^{2}=97 \%$

Test for overall effect: $z=6.21(P<0.001)$

\section{HR $(95 \% \mathrm{CI})$ \\ $2.85(2.55-3.18)$ \\ $1.74(1.66-1.83)$ \\ $2.19(2.06-2.34)$ \\ $2.21(1.72-2.83)$ \\ $(0.09-53.94)$}

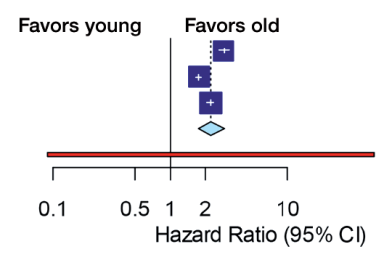

Sex at 5 years

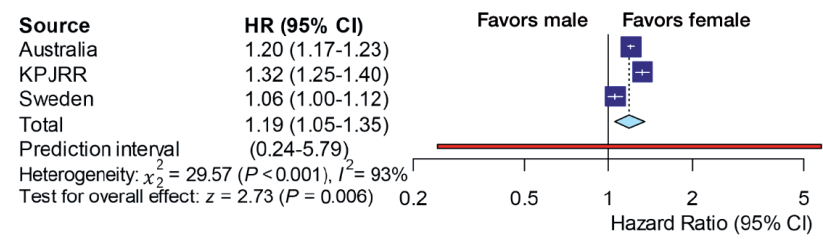

Sex at 10 years

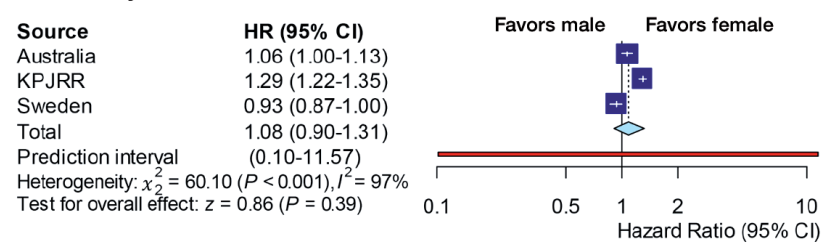

Sex at 15 years

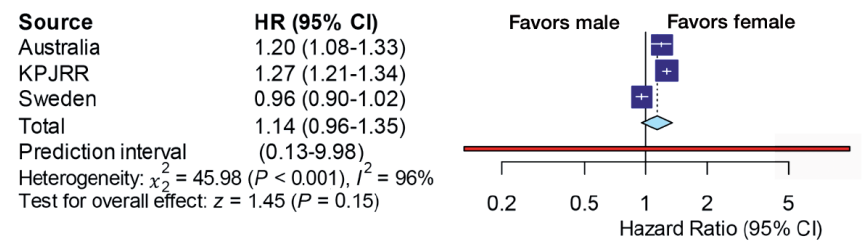

ASA at 5 years

$\begin{array}{ll}\text { Source } & \text { HR }(95 \% \mathrm{Cl}) \\ \text { Australia } & 1.20(1.15-1.26) \\ \text { KPJRR } & 1.32(1.25-1.40) \\ \text { Sweden } & 1.37(1.26-1.49) \\ \text { Total } & 1.29(1.19-1.39) \\ \text { Prediction interval } & (0.50-3.29) \\ \text { Heterogeneity: } x_{2}^{2}=10.40(P=0.006), I^{2}=81 \% \\ \text { Test for overall effect: } z=6.27(P<0.001)\end{array}$

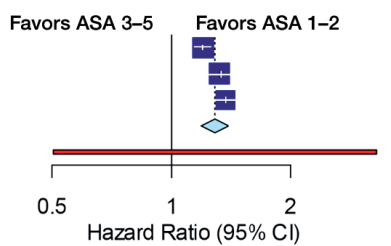

BMI at 5 years

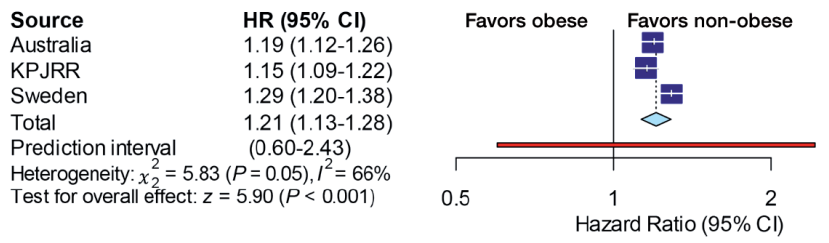

Figure 3. Patient factors meta-analysis. 
Prosthesis constraint at 5 years

$\begin{array}{ll}\text { Source } & \text { HR }(95 \% \mathrm{Cl}) \\ \text { Australia } & 1.23(1.20-1.27) \\ \text { KPJRR } & 1.18(1.11-1.26) \\ \text { Sweden } & 1.75(1.59-1.93) \\ \text { Total } & 1.36(1.07-1.73) \\ \text { Prediction interval } & (0.06-29.74) \\ \text { Heterogeneity: } x_{2}^{2}=48.89(P<0-001), I^{2}=96 \% \\ \text { Test for overall effect: } z=2.53(P=0.01)\end{array}$

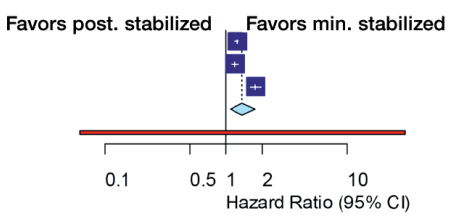

Prosthesis constraint at 10 years

$\begin{array}{ll}\text { Source } & \text { HR }(95 \% \mathrm{Cl}) \\ \text { Australia } & 1.23(1.16-1.32) \\ \text { KPJRR } & 1.17(1.11-1.24) \\ \text { Sweden } & 1.65(1.47-1.86) \\ \text { Total } & 1.33(1.09-1.63) \\ \text { Prediction interval } & (0.10-17.36) \\ \text { Heterogeneity: } \chi_{2}^{2}=25.93(P<0.001), I^{2}=92 \% \\ \text { Test for overall effect: } z=2.76(P=0.006)\end{array}$

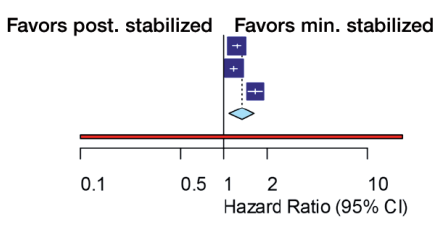

Prosthesis constraint at 15 years

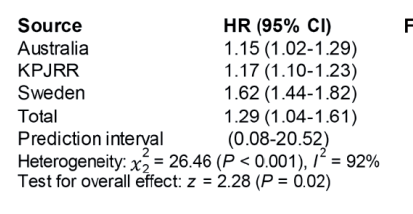

Test for overall effect: $z=2.28(P=0.02)$

\section{Fixation at 5 years}

$\begin{array}{ll}\text { Source } & \text { HR }(95 \% \mathrm{CI}) \\ \text { Australia } & 1.31(1.27-1.36) \\ \text { KPJRR } & 1.44(1.20-1.73) \\ \text { Sweden } & 1.31(1.14-1.51) \\ \text { Total } & 1.32(1.28-1.36) \\ \text { Prediction interval } & (1.06-1.63) \\ \text { Heterogeneity: } x_{2}^{2}=1.00(P=0.61), I^{2}=0 \% \\ \text { Test for overall effect: } z=16.37(P<0.001)\end{array}$
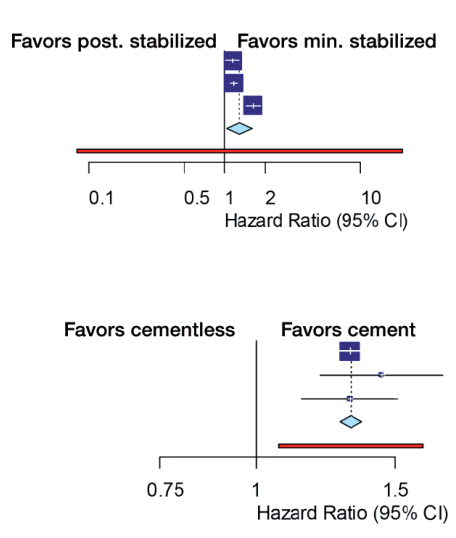

\section{Fixation at 10 years}

$\begin{array}{lc}\text { Source } & \text { HR }(\mathbf{9 5} \% \mathrm{Cl}) \\ \text { Australia } & 1.01(0.94-1.08) \\ \text { KPJRR } & 1.47(1.25-1.72) \\ \text { Sweden } & 1.43(1.21-1.68) \\ \text { Total } & 1.27(0.99-1.63) \\ \text { Prediction interval } & (0.06-27.31) \\ \text { Heterogeneity: } x_{2}^{2}=27.55(P<0.001), l^{2}=93 \% \\ \text { Test for overall effect: } z=1.91(P=0.06)\end{array}$

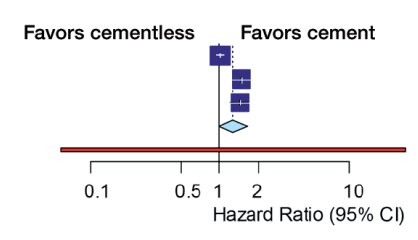

Fixation at 15 years

$\begin{array}{ll}\text { Source } & \text { HR }(95 \% \mathrm{CI}) \\ \text { Australia } & 1.12(0.99-1.27) \\ \text { KPJRR } & 1.44(1.23-1.68) \\ \text { Sweden } & 1.48(1.26-1.74) \\ \text { Total } & 1.33(1.11-1.59) \\ \text { Prediction interval } & (0.17-10.65) \\ \text { Heterogeneity: } x_{2}^{2}=9.39(P=0.009), I^{2}=79 \% \\ \text { Test for overall effect: } z=3.16(P=0.002)\end{array}$

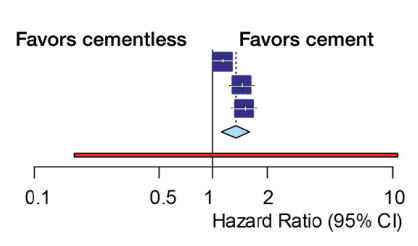

Figure 4. Prosthesis factors meta-analysis.

\section{Bearing mobility at 5 years}

$\begin{array}{ll}\text { Source } & \text { HR }(95 \% \mathrm{Cl}) \\ \text { Australia } & 1.37(1.33-1.42) \\ \text { KPJRR } & 1.37(1.24-1.51) \\ \text { Sweden } & 2.19(1.76-2.72) \\ \text { Total } & 1.58(1.18-2.10) \\ \text { Prediction interval } & (0.04-59.27) \\ \text { Heterogeneity: } x_{2}^{2}=17.22(P<0.001), I^{2}=88 \% \\ \text { Test for overall effect: } z=3.10(P=0.002)\end{array}$

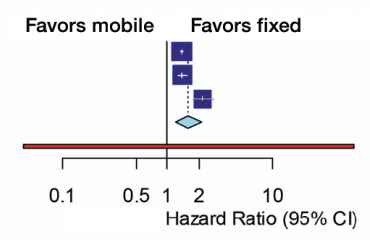

Bearing mobility at 10 years
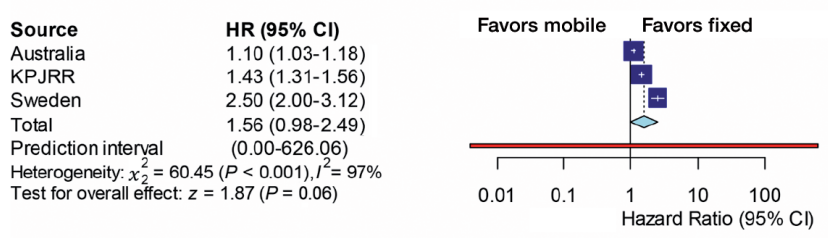

Bearing mobility at 15 years

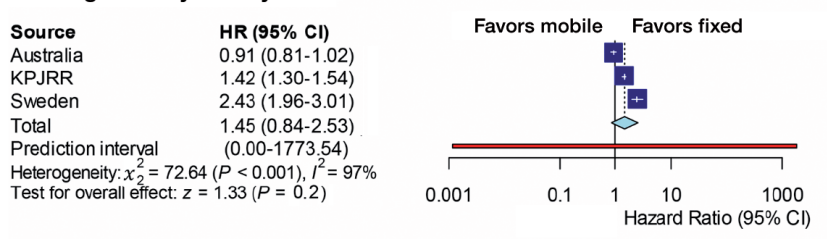

Patella component usage at 5 years

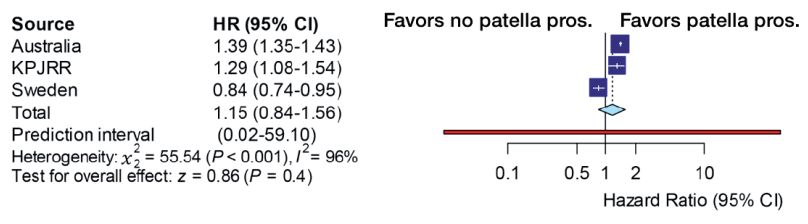

Patella component usage at 10 years

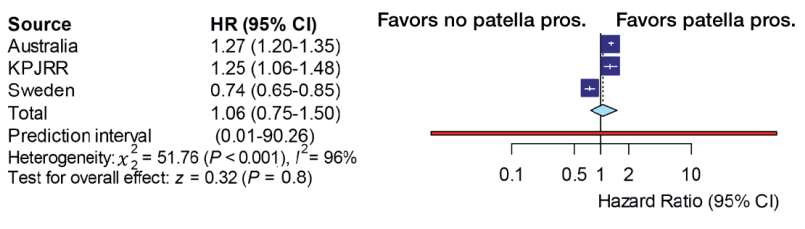

Patella component usage at 15 years

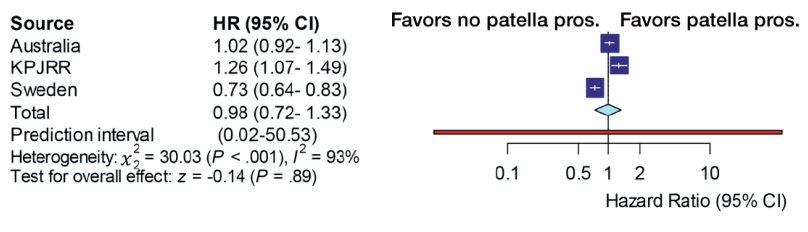

\section{Polyethylene type 5 years}

$\begin{array}{ll}\text { Source } & \text { HR }(\mathbf{9 5} \% \mathrm{Cl}) \\ \text { Australia } & 1.35(1.31-1.39) \\ \text { KPJRR } & 1.03(0.96-1.10) \\ \text { Sweden } & 0.83(0.76-0.90) \\ \text { Total } & 1.05(0.79-1.39) \\ \text { Prediction interval } & (0.03-37.74) \\ \text { Heterogeneity: } x_{2}^{2}=148.10(P<0.001), I^{2}=99 \% \\ \text { Test for overall effect: } z=0.34(P=0.8)\end{array}$

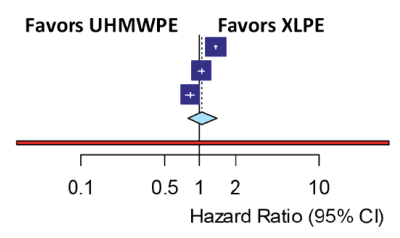

Polyethylene type 10 years

$\begin{array}{ll}\text { Source } & \text { HR } \mathbf{( 9 5 \% ~ C l )} \\ \text { Australia } & 1.55(1.42-1.68) \\ \text { KPJRR } & 1.04(0.98-1.10) \\ \text { Sweden } & 0.97(0.87-1.08) \\ \text { Total } & 1.16(0.87-1.54) \\ \text { Prediction interval } & (0.03-45.38) \\ \text { Heterogeneity: } x_{2}^{2}=68.26 & (P<0.001), l^{2}=97 \% \\ \text { Test for overall effect: } z=1.01(P=0.3)\end{array}$

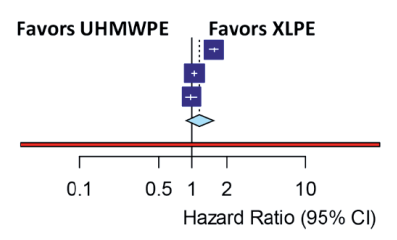




\section{Dear colleagues and friends of the Knee Society}

It is with a sad heart that I am writing to inform you of the passing of my friend and mentor, Otto Robertsson. Otto passed away suddenly in his home town of Reykjavik, Iceland, on Saturday, October 2nd. He was 68 years old and is survived by his dear wife Elin, his three daughters, and his four grandchildren, all of whom he adored.

Otto attended medical school in Aarhus, Denmark, from which he graduated as an MD in 1982. After returning to Iceland for a few years he then moved to Sweden for specialist training and received authorization as an orthopaedic surgeon in 1989. He started working at the University Hospital in Lund in 1990 and soon became involved in the Swedish Knee Arthroplasty Register (SKAR). Otto managed the SKAR, since 1996, for almost 25 years. Under his leadership the register became a well-respected and preeminent arthroplasty register with international recognition. As early as 1997, Otto was a pioneer in initiating PROMs data collection in the SKAR. It was with these efforts that I first met Otto and had the great privilege to study at his side. We published numerous papers together under his vision and direction.

Otto was the general secretary of the Icelandic Orthopaedic Society in 2003-2011, represented Iceland in EFORT and was the congress president of both the Nordic Orthopaedic Federation and the 7th congress of International Society of Arthroplasty Registries (ISAR) in Reykjavik 2018. Otto was a founding member and passionate supporter of ISAR. His efforts and outstanding contributions were recognized in 2020 when he received the ISAR Lifetime Achievement Award; a fitting recognition of his lasting and impactful contributions to registry science.

In 2000 Otto defended his doctoral thesis (PhD) "The Swedish Knee Arthroplasty Register - Validity and Outcome" at Lund University. He authored over 100 publications, mostly based on register work, many of them in high impact journals. Otto was a frequent lecturer at national and international orthopaedic conferences. He was involved in several $\mathrm{PhD}$ studies including SKAR data over the years. Otto was internationally well respected and was granted membership in the Knee Society in 2012.

Otto had a deep knowledge of modern statistical methods and was an excellent scientific writer, only accepting perfection before submitting a study for publication. He was a rigorous methodologist, a keen debater, and frankly, a brilliant mind. Despite his most impressive accomplishments, he shunned the spotlight and accolades and was a role model of humility.

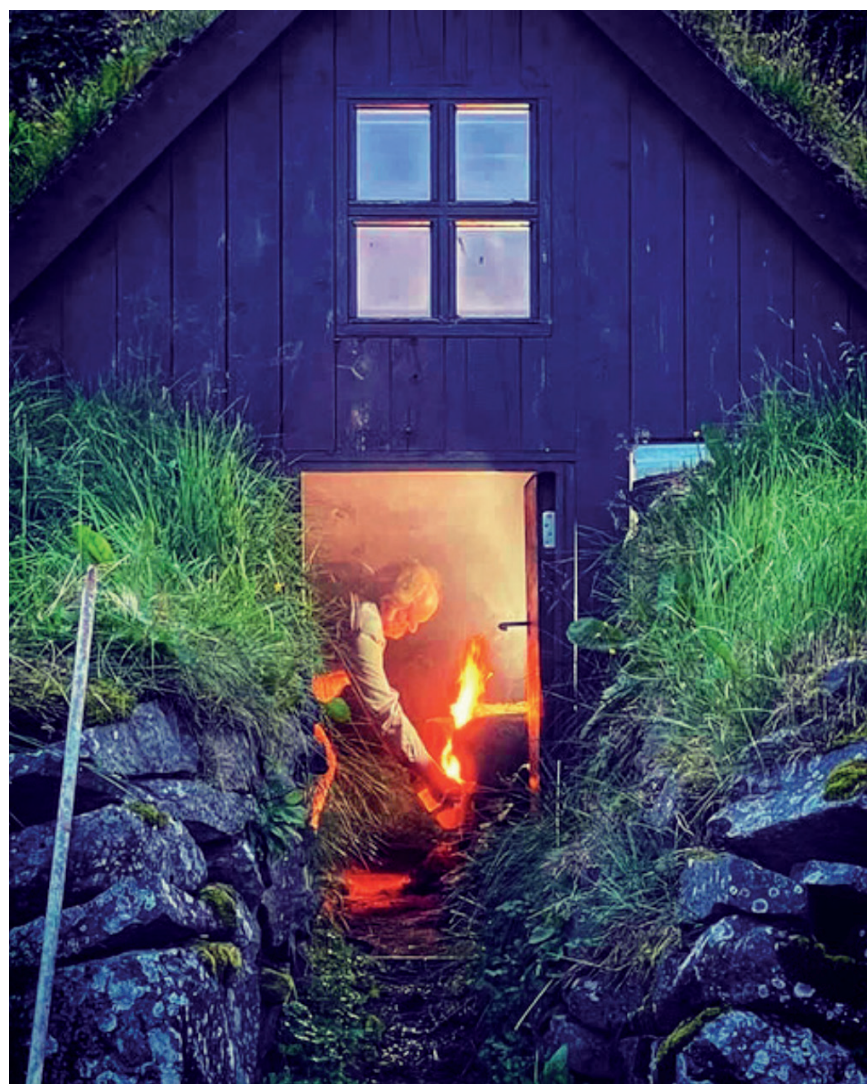

Otto smoking salmon in his smoke house at his summer home in Iceland, August, 2021.

Otto loved his family summer house in Iceland where he shared time with his beloved family and friends. He was well known for his smoked salmon that he caught in the glacial river by his summer house and hay smoked on his property. He enjoyed nature and sharing a good whiskey or cognac with friends, ideally shared with his salmon or a roasted leg of Icelandic lamb.

Otto was a gracious and generous friend with a huge heart. I, like so many others, will miss him deeply for having left us too soon but my heart swells and a smile comes to my face when I reflect back on the many great moments we shared. I am a better person for having known him and I will personally remember him by doubling my efforts to be a better surgeonscientist, and more importantly, a better friend.

Please take the time to spare a moment of reflection for Otto. Also, take a moment to reach out and say hi to your friends as life is short and friends are so precious. I miss you deeply and will remember you always, my dear friend.

\section{Michael Dunbar}

